\title{
Percutaneous Electrolysis: A Potential Tool for Myofascial Pain Syndrome Treatment?
}

\author{
Juan Antonio Valera Calero* \\ Department of Physiotherapy, Faculty of Education and Health. Camilo José Cela University, Spain \\ *Corresponding author: Juan Antonio Valera Calero, Department of Physiotherapy, Faculty of Education and Health, \\ Camilo José Cela University, Avenida de las Suertes 62 2-4 (28051) Madrid, Spain
}

\begin{tabular}{|c|c|}
\hline ARTICLE INFO & Abstract \\
\hline Received: 幽 May 11, 2020 & Citation: Valera-Calero JA. Percutaneous Electrolysis: A Potential Tool for Myofascial \\
\hline Published: 幽 May 19, 2020 & 20. BJSTR. MS.I \\
\hline
\end{tabular}

\section{Mini Review}

Myofascial Pain Syndrome (MPS) is a common pain condition characterized by the presence of myofascial trigger points (TrPs) which are defined as "a hyperirritable spot in skeletal muscle that is associated with a hypersensitive palpable nodule in a taut band. This spot is painful on manual compression and can give rise to characteristic referred pain, referred tenderness, motor dysfunction and autonomic phenomena"[1]. Although there are no laboratory test or imaging studies to diagnose $\operatorname{TrP}$ presence, could be identified by electromyography, myotonometry or manual palpation.Several studies tried to understand the $\operatorname{TrP}$ pathophysiology as well as provide effective treatments to reduce pain and disability. At least one part of the TrP nociceptive input is caused by ischemia and hypoxia due to the capillary vessel's compression by the taut bands [2]. Low blood oxygen levels results in a $\mathrm{pH}$ reduction (acidification) to [3-5] and this cause an activation of acid-sensing ion channels (ASIC) receptors, acetylcholinesterase inhibition [5] and stimulation of ATP, bradykinin, tumor necrosis factor alfa, interleukins, serotonin, noradrenaline, P substance and calcitonin gen-related peptide [4].All the MPS treatments studied match in the TrPs inactivation, restoring the normal muscle length and eliminating or correcting factors that created or perpetuated those TrPs.

Although some manual therapies (such as ischemic compression, spray and stretch, strain and counterstrain, muscle energy techniques, trigger point pressure, and transverse friction massage...) and non-invasive non-manual therapies (such as electrical stimulation, ultrasound, laser, magnet therapies, instrumental assisted therapies...) have been described, this mini- review will focus on invasive therapies. TrPs can be effectively inactivated by inserting a needle with or without local anesthesic injections into the TrP zone (deep dry needling) or around (superficial dry needling) [6].In the last years, this mechanic input has been combined with a galvanic current through the needle (which is the negative electrode) [7]. This Percutaneous Electrolysis (PE) technique is a minimally invasive technique induces a electrochemical reaction in the area where the ultrasound-guided needle is placed and increases the $\mathrm{pH}$ and cellular necrosis8. Although different devices has been launched (Intratissue Percutaneous Electrolysis $\left(\mathrm{EPI}^{\circledR}\right)$, Therapeutic Percutaneous Electrolysis (EPTE ${ }^{\circledR}$ ) or Physio Invasiva ${ }^{\circledR}$ ), the concept is the same modifying the products of the charge (Q): Intensity (I) and time ( $\mathrm{t}$ ). This tool has been studied for several tendinopathies conditions combined with eccentric exercise obtaining good results in patients with subacromial pain syndrome [8], patellar tendinopathy [7] and plantar fasciosis [9]. Although is known that TrPs are in an acid medium produced by ischemia and hypoxia2, few studies assessed the PE effects on MPS.

The first of the two studies found about this topic [10], assessed the ultrasound-guided PE on levator scapulae muscle in patients with acute whiplash syndrome. The application of PE demonstrated an effective improvement in pressure-pain threshold; quality of life and subjective neck pain perception, but no differences were found with the application of combined microwave thermotherapy, TENS current, massage therapy, therapeutic ultrasound and active scapulo-thoracic exercises after 5 weeks. However, to obtain the same improvement, less treatment sessions were applied for the 
PE group and this could be a good cost-effective treatment option in chronic diseases.The second study applied PE on lateral pterygoid muscle in patients with temporomandibular myofascial pain [11]. In this case, PE obtained greater and earlier results on pain reduction at rest, during chewing, and for maximum interincisal opening compared with sham dry needling up to 28,42 and 70 days. When comparing PE with dry needling, differences were found for pain at rest at days 28 and 42 but at day 70; for maximal interincisal opening at days 28,42 and 70 and functionality at day 70 . However, no differences were found for pain on mastication or functionality at days 28 or 42 .

Although the galvanic electrical current could apparently be painful, surprisingly no differences in subjective tolerance to treatment have been reported between PE and dry needling. Two studies are not enough to recommend PE during the clinical practice, but it has been shown as a promise method to improve pain and disability. It is necessary report the effects of this technique on different conditions potentially susceptible of application (especially chronic conditions). Also some Q, I and t references are provided for tendinopathy treatments, but there is not enough evidence comparing the application of high and low intensity PE. In a recent conference, it was reported that the application of high intensity (3 mA x 3") and low intensity (0,3mA x 30") PE induced an improvement in subjective shoulder pain perceived and range of movement with no differences between methods Just a difference in the tendon thickness was found for the high intensity PE group [12], but no relation between tendon thickness and clinical characteristics are reported [13]. In TrP application, current doses applicated were $2 \mathrm{~mA}$ for 3 seconds, three times 11 and $2 \mathrm{~mA}$ increasing $1 \mathrm{~mA} / \mathrm{sec}$ to reach $4 \mathrm{~mA} 10$. Therefore, there is an evidence need to determine optimal $\mathrm{Q}, \mathrm{I}$ and $\mathrm{t}$ references and comparisons to obtain optimal results both in tendinopathies and MPS conditions; the efficacy of PE on different conditions (especially those chronic with worst prognosis) and the potential effects on local biochemical responses.

\section{References}

1. Fernándezde Las Peñas C, Dommerholt J (2018) International Consensus on Diagnostic Criteria and Clinical Considerations of Myofascial Trigger Points: A Delphi Study. Pain Med19(1): 142-150.

ISSN: 2574-1241

DOI: $10.26717 /$ BJSTR.2020.27.004550

Juan Antonio ValeraCalero. Biomed J Sci \& Tech Res

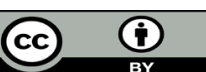

This work is licensed under Creative Commons Attribution 4.0 License

Submission Link: https://biomedres.us/submit-manuscript.php
2. Sikdar S, Ortiz R, Gebreab T, Gerber LH, Shah JP (2010) Understanding the vascular environment of myofascial trigger points using ultrasonic imaging and computational modeling. Conf Proc IEEE Eng Med Biol Soc: 5302-5305.

3. Shah JP, Phillips TM, Danoff JV, Gerber LH (1985) An in vivo microanalytical technique for measuring the local biochemical milieu of human skeletal muscle. J Appl Physiol 99(5): 1977-1984.

4. Shah JP, Danoff JV, Desai MJ, Parikh S, Nakamura LY, et al. (2008) Biochemicals associated with pain and inflammation are elevated in sites near to and remote from active myofascial trigger points. Arch Phys Med Rehabil 89(1): 16-23.

5. Gerwin RD, Dommerholt J, Shah JP (2004) An expansion of Simons' integrated hypothesis of trigger point formation. Curr Pain Headache Rep 8(6): 468-475.

6. Saxena A, Chansoria M, Tomar G, Kumar A (2015) Myofascial pain syndrome: An overview. J Pain Palliat Care Pharmacother 29(1): 16-21.

7. Abat F, Gelber PE, Polidori F, Monllau JC, SanchezIbanez JM (2015) Clinical results after ultrasound-guided intratissue percutaneous electrolysis (EPI $囚$ ) and eccentric exercise in the treatment of patellar tendinopathy. Knee Surg Sports TraumatolArthros 23: 1046-1052.

8. AriasBuria JL, TruyolsDomínguez S, ValeroAlcaide R, SalomMoreno J, AtinArratibel MA, et al. (2015) Ultrasound-Guided Percutaneous Electrolysis and Eccentric Exercises for Subacromial Pain Syndrome: A Randomized Clinical Trial. Evid Based Complement Alternat Med 2015: 315219.

9. IborraMarcos Á, RamosÁlvarez JJ, Rodriguez Fabián G, et al. (2018) Intratissue Percutaneous Electrolysis vs Corticosteroid Infiltration for the Treatment of Plantar Fasciosis. Foot Ankle Int. 39(6): 704-711.

10. García Naranjo J, Barroso Rosa S, Loro Ferrer JF, LimiñanaCañal JM, Suarez Hernández E (2017) A novel approach in the treatment of acute whiplash syndrome: Ultrasound-guided needle percutaneous electrolysis. A randomized controlled trial. OrthopTraumatolSurg Res103(8): 1229-1234.

11. Lopez Martos R, Gonzalez Perez LM, Ruiz Canela Mendez P, Urresti Lopez FJ, Gutierrez Perez JL, et al. (2018) Randomized, double-blind study comparing percutaneous electrolysis and dry needling for the management of temporomandibular myofascial pain. Med Oral Patol Oral Cir Bucal 23(4): e454-e462.

12. ValeraCalero JA, NuñezIzquierdo J, DelgadoDelgado $R$, Cimadevilla Fernández-Pola E Tratamientocomparativo de electrólisispercutáneaaaltas y bajasintensidadesentendinopatía del supraespinoso. I CongresoInternacional de FisioterapiaInvasiva y Musculoesquelética.

13. Navarro Ledesma S, Struyf F, Falla D, LuqueSuarez A (2019) Nontraumatic chronic shoulder pain is not associated with changes in rotator cuff interval tendon thickness. Clin Biomech (Bristol, Avon) 63: 147-152.

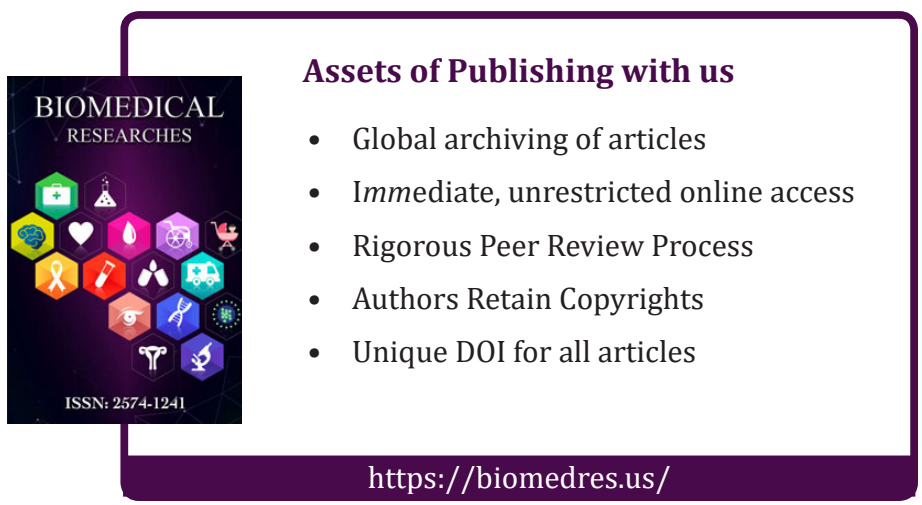

